\title{
ФОРМИ И МЕТОДИ НА ГЛОБАЛНО СЫПЕРНИЧЕСТВО В СЪВРЕМЕННИЯ СВЕТОВЕН РЕД
}

\author{
Владислав Лазаров
FORMS AND METHODS OF GLOBAL RIVALRY IN THE CONTEMPORARY WORLD ORDER
Vladislav Lazarov

\begin{abstract}
Modern dynamics in society necessitates a new understanding of the concept of security, achieved as a result of a comprehensive strategic analysis. Creating an adequate vision of national security in the global age requires a paradigm shift in the way people think. Contemporary society and realities demand the formation of a new type of personality - a citizen of the 21st century who is informed, competent, educated, a democrat, a patriot, accountable to the country and to himself, while being a cosmopolitan at the same time. The article addresses issues of national security as part of cultural identity.
\end{abstract}

Key words: national security, state, nation, cultural identity

DOI: https://doi.org/10.46687/DVWG9838

\section{Геополитически измерения на световния ред}

Понятието „световен ред“ е ново. То е опозиция на т. нар. Студена война или „стар световен ред“. В този смисъл понятието може да се употребява и с определена историческа давност. В смисъла на „геополитически ред“ го срещаме в най-новата литература, анализираща социалната промяна през XX в.

За разлика от времето на традиционните общества, съвременните геополитически представи приближават историята до международните отношения, в които елитарни политически групи вземат решения, засягащи едновременно цялото общество. В политиката за сигурност един от важните компоненти е геополитическият, а неговата сърцевина е контрольт над стратегическите ресурси. Очевидно е, че динамиката на световната политика е „сьревнование“ за ресурси. Това е основата на икономоцентристкия подход в сферата на сигурността. И ако визията на Фридман, че ресурсните спорове ще се решават чрез пазарни механизми, е водеща за съвременните неолиберални теории в международните отношения, то реалността демонстрира и друг ракурс в реализацията на „жизнено важните национални интереси“.

Всяка държава, независимо дали е силна или слаба, се стреми да защити надеждно своите интереси. Политиката на всяка държава се 
осъществява винаги в неин интерес. Отбранителната слабост никога не е залог за сигурност и винаги е била потенциален притегателен фактор за агресия. Разликата във възможностите на големите и малките държави да спомагат за укрепването или за подкопаването на международната сигурност е очевидна. Единствено големите държави са в състояние да водят глобална политика. Делегирането на защитата на сигурността изключително на големите държави поражда неравенство и открива широк простор за силата в международната практика. Светът в последно време успешно се освобождава от убеждението, че сигурността в международните отношения е грижа на големите. Факт е, че ресурсите на малките държави са ограничени и влиянието им върху процесите не е голямо. Ето защо е редно опитите за защита на националните интереси да се реализират между баланса на интересите на водещите геополитически играчи. Интересен казус е, че тази тенденция е осъзната от някои български политици още в началото на XX век (Georgiev 2016: 472-474).

Балансът на интересите при изграждането на отношенията с други нации обхваща на практика главните сфери на международните отношения:

икономическите отношения, свързани с пазари, инвестиране на капитал, международна интеграция;

политическите отношения - създадени съюзи, отношения на партньорство, недопускане на зависимост и попадане в сфера на чуждо влияние;

- $\quad$ военните отношения - коалиране или отказ от коалиране във военно-политически формирования и съюзи с регионална и национална насоченост, стил и организация на изграждане на собствените въоръжени сили;

- $\quad$ активен и пасивен неутралитет при кризисни регионални и извънрегионални ситуации.

С какви „инструменти“ реализират геополитическите си амбиции основните играчи на „голямата шахматна дъска“?

\section{Съвременен инструментариум за натиск и влияние}

Хибридни войни - използване на неконвенционални средства за постигане на стратегически цели. Комбинира симетрични и асиметрични действия с прилагане на информационни и психологически операции.

Цели: 


\section{Годииник на ФХH, XXXII A}

- завземане на властта за пренасочване на ресурсите в чужд интерес (противопоставя недържавни формации срещу държавата);

- промени в националния манталитет на нацията, обект на агресията, и спечелването ѝ за своята цивилизационна култура в бъдеще.

Методи за борба срещу хибридната война:

- политически диалог, стабилна политическа система;

- патриотично възпитание;

- информационни операции за противодействие.

Асиметрични конфликти - характеризират отношенията между несъпоставими по мощ и статут противници, като при конфликт послабата страна налага изгоден начин за развитието му и постига политическа победа.

Към асиметричните конфликти се причисляват партизанските войни, колониалните управления, национално-освободителните движения, войните във Виетнам, Афганистан, Ирак и др.

Характерни черти:

- неспособност на „силния“ да отстои позицията си безапелационно;

- възможност на „слабия“ с малки инвестиции да нанесе сериозни поражения.

Мека сила - Soft power - метод на хегемония чрез привличане и сътрудничество, форма на въздействие от политическата власт на държавата и постигане на резултати чрез доброволност. Създава необходимите условия на глобалните играчи за активни „мирни“ операции за разместване на геополитическите пластове по света.

Основни инструменти за реализация:

- култура;

- политическа идеология;

- външна политика.

„Цветни“ революции - практическата реализация на политиката на „меката“ сила. Те са технология на политически шантаж, прикрит като стихиен процес. Техен обект е властта, а предмет е политическият режим. Динамиката на организацията се определя от регионалните характеристики и националните особености на страната, в която се осъществяват, а цената - от ресурсите и технологичния потенциал на противника. В книгата си „Информация и сигурност“ Ст. Денчев дава актуалните теории и насоки, свързани с въпросите „Кой разбърква боите и кои са художниците“ (Denchev 2019: 297), в ракурса на съвременните проблеми на националната и международна сигурност. 
От емпирична гледна точка относно етапите на реализация на цветните революции - делегитимиране и овладяване на властта, дискредитиране на силовите структури и държавния апарат - особено актуален е трудът на Антон Златанов „Теоретични и правни аспекти на дейността на полицейските органи по осигуряване на обществения ред при масови мероприятия“ (Zlatanov 2016: 59-74).

„Горещи точки“ - локален, въоръжен конфликт, част от етнически, политически, икономически, териториален спор на регионално ниво. Въоръженото противопоставяне е между държави или социални общности в самите тях (например Чечения).

Характеристики:

- политическите цели са предварително известни;

- бойните действия се водят на ограничена територия;

- в конфликта се използва ограничен военен арсенал;

- бойните действия не могат да бъдат прекратени само по политическата воля на едната страна.

Терминът е характерен за руската неокласическа геополитическа лексика, а английският израз „Hot spot““ има различно значение.

„Замразени“ конфликти - ситуация в международните отношения, при която възникналите противоречия между страните се прекратяват без подписване на мирен договор и без политическо разрешаване на конфликта. Използва се за обозначение на неразрешени териториални конфликти. Днес е част от доктринизирания инструментариум на съвременната руска геополитическа школа, но реално съществува още през второто десетилетие на XX век и дори се проявява на Балканите (Georgiev /1/ 2018: 42-59).

Актуални съвременни примери за „замразени“ конфликти:

- Арабско-израелският конфликт;

- Корейското разделение;

- индийско-пакистанските конфликти;

- Кипърският въпрос;

- конфликтите в постсъветското пространство;

- наследството на постюгославското пространство.

Рискове и заплахи за управлението на стратегическите ресурси от гледна точка на държавния контрол

Частни военни компании (ЧВК)

От края на $\mathrm{XX}$ век се развива тенденция на девалвиране на монопола на държавата върху силата и силовата политика в 


\section{Годишник на ФХH, XXXII A}

международните отношения. Устойчива тенденция е т. нар. proxy war, „война с чужди ръце“ (Mumford 2013: 141). Клиент на ЧВК е държавата. Приемащата ги държава носи отговорност за действията на ЧВК на нейна територия. На свой ред държавата, чието седалище е ЧВК, е длъжна да упражнява общ контрол над дейността им. От гледна точка на международното право служителите на ЧВК са граждански лица, поради което в ред случаи тяхната дейност може да се разглежда като „наемничество“. Те нямат право да вземат участие в бойни действия в състава на редовни въоръжени формирования, но имат право да използват оръжие при самозащита и при защита на сигурността на поверените им обекти, имущество и хора. Само че в реалността те не се занимават с охрана или придружаване на обекти, а изпълняват военни задачи заедно с националните въоръжени сили (Сирия, Либия, Ирак, Афганистан и т. н.). В съвременните международни отношения властимащите се нуждаят от инструмент, който да действа концентрирано, решително и да не е пряко свързан с държавата. Този инструмент трябва да позволи на страната да решава задачи зад граница, без от това да произтичат шокови политически последици. ЧВК все по-широко ще участват в реализирането на държавната политика на различните етапи от конфликтите. Те не само минимизират политическите рискове за страните, постигащи чрез тях своите интереси, но и регламентират поддържката на редовни и паравоенни структури, които по външни или вътрешнополитически причини биха били неприемливи.

Преимуществата на ЧВК пред регулярните въоръжени сили са:

- използването им не предизвиква сред обществата такова недоволство, каквото би породило ползването на регулярни въоръжени сили;

- представляват противовес на местните въоръжени сили в държави със слаби политически институции;

- мобилни са, имат гъвкаво оперативно управление без бюрокрация;

- загубите на личен състав на ЧВК не се отчитат в официалните статистики;

- имат по-висок професионализъм в сравнение с регулярните формирования (професионализмът в сравнение с контрактни войски е под въпрос).

Недостатьци:

- липсва идейна и идеологическа мотивация на личния състав; 
- условията на контрактите в ЧВК не предвиждат всички варианти за развитие на ситуацията;

- отсъства единен план за мероприятия и единен оперативен центьр за управление на войските и ЧВК;

- отсъства обмяната на информация или тя е с непълни данни от оперативен характер.

ЧВК на практика възникват преди повече от едно столетие и са използвани и в България ${ }^{1}$. Те работят с практически всички субекти на съвременната геополитика - правителства, ТНК, НПО, ООН, Световната банка и т.н.

Макар и постоянни играчи в почти всички съвременни конфликти, ЧВК са далеч от силовите възможности на големите играчи. В миналото типичен пример за ЧВК е „Източно-индийската компания“. Днес американските „Military Professional Resources“, „Academi“, руските „Группа Вагнер“, „Славянский корпус“, британската G4S и др.

\section{Тероризъм}

Основните заплахи, свързани с международния тероризъм, произтичат от: вероятността от наличие на „спящи“ терористични клетки; извършването на терористични актове, мотивирани от действия за самоопределение или независимост на етнически и/или религиозни групи; настъплението на религиозния екстремизъм и установената в международен план тенденция за проникването му под прикритието на благотворителни организации, фондации, учебни центрове; възможна симбиоза между терористични формирования и структури на организираната престьпност в сфери като трафик на оръжие и общоопасни средства, наркотрафик и пране на пари. В явлението се съчетават политически, икономически, идеологически, религиозни, социални и правни аспекти. Но, както твърди академик Примаков: „Освободителната борба и тероризмът са различни, несъвпадащи понятия. Тяхното обединение не може да има никакви оправдания“ (Primakov 2007). Това действително е така. Още в навечерието на Пьрвата световна война българското националноосвободително движение в Македония многократно е несправедливо обвинявано от мощните

1 Пример за такава организация е Върховният македонски комитет (впоследствие ВМОК), създаден през 1895 г. Той е използван активно от българското правителство през с. г., а през 1900 г. създава специални стрелкови дружества (Georgiev 2007: 364367, 374-376 и цит. лит.). 


\section{Годишник на ФХH, XXXII A}

пропаганди на съседните балкански държави в тероризъм (Ilchev 1995: 137-149; Georgiev /2/ 2018: 42-59).

Доктринерски източниците на тероризма се формират от две течения:

- „философия на бомбата“ - според Карл Хайнцген мощно оръжие за създаване на хаос;

- „пропаганда на делото“, „средство за радикално подобряване на обществото“ (Бакунин) или подбуда към бунт по пътя на терора.

Видове тероризъм:

- религиозен - края на XVIII, XIX, началото на XX век;

- националсепаратистки - нараства след 1880-90 г., включително на Балканите (Georgiev /3/ 2018: 147-178);

- ислямски - 1970-80 г., с най-радикална форма уахабизъм;

- държавен - от „нощта на дългите ножове“ до „поддържан от държавата тероризъм“ без прякото ѝ участие.

Методите на борба на различните видове тероризъм са общи, но целите са различни.

Методите на противодействие срещу тероризма са:

- решаване на социално-икономически проблеми;

- идеологическо „разобличение“ на идеите на терористичните групировки;

- адекватно координиране и действия на силовите структури.

Пиратството като явление по формите си на проява, по някои причини за възникване, както и по силите, стоящи зад него, прилича на тероризма. От момента на появата си като риск за комуникациите и тьрговските процеси е прието за форма на шантаж и ,престьпление срещу международното право“. В същото време няма международна правна система за пиратството, въпреки че резолюция на Съвета за сигурност на ООН дава право на отделните държави да преследват пирати и да съдят заловените нарушители по дефиницията ,универсално престъпление“. И ако методите на пиратите остават относително непроменени днес, то мерките срещу тях от миналото (Georgiev 2020: 118-139) вече са неприложими. Съвременното международно законодателство гарантира своеобразен комфорт за морските разбойници. Днес е активно практикувано в Аденския залив, предимно в акваторията на Сомалия.

Методи за противодействие:

- анализ на социалния генезис на пиратството; 
- правно-нормативна рамка за класификация на признаците и действията на нарушителите;

- засилено военно присъствие в рисковите зони;

- координираща и организационна роля на ангажираните световни организации (ОOH - Съвет по безопасност и др.).

\section{Миграция}

„Имиграцията не е нито „добра“, нито „лоша“. Но ако потоците не се контролират, това поражда социални, териториални и културни разцепления, които наблюдаваме днес...“ (Fukuyama 2018).

Неотдавнашните събития около миграционната криза от 20142015 г. бяха сериозно предизвикателство за суверенитета и сигурността на ред държави, членки на НАТО и ЕC, и подложиха на изпитание вътрешния ред и геополитическия им статус в мирно време без военна заплаха.

Нелегалната миграция като явление е свързана с националната сигурност. Оказва влияние от политически, социално-културен, правоохранителен аспект. От една страна, тя разширява националните граници на трудовия пазар и решава икономически въпроси както на приемащата, така и на изпращащата страна. От друга, безконтролните трансгранични потоци създават проблеми за вътрешната и външната политика. Явлението нелегална миграция се оказа и практичен инструмент за влияние на полето на международните отношения. Насочването и интензифицирането на миграционните потоци с цел решаване на геополитически казуси не е нестандартен инструмент за „голямата игра“. Подобна ситуация от началото на 2020 г. онагледи за пореден път слабостта на колективния защитен рефлекс на ЕC пред предизвикателството на турската страна и накара европейските страни да преговарят с Турция.

В съвременните условия възможна оптимизация на миграционните потоци може да се постигне чрез:

- съкращаване на нелегалния сектор;

- либерализация на селективната трудова миграция.

\section{Транснационални компании (ТНК)}

Тенденция в конструкцията на съвременния неолиберален модел на глобалната „шахматна дъска“ е мощната поява на международната арена на ред недържавни транснационални актьори (ТНА) като 


\section{Годишник на ФХH, XXXII A}

транснационални компании (ТНК) и неправителствени организации (НПО), които:

- обхващат практически всички сфери, дори и традиционно държавни;

- разширяват ареала си на действие до планетарни размери;

- въвличат крупни маси в транснационален бизнес;

- пресичат функциите си с държавата.

Те са икономическата основа на глобалната икономика. Противник са на административните ограничения, противопоставят се на опитите за контрол от страна на националните правителства. ТНК провеждат самостоятелна силова политика без своите правителства, но не и срещу тях - форма на зависимост на новите актьори от държавите.

Историята от последния четвърт век показва, че нерядко ТНК реализират икономическа политика и норми на поведение чрез собствено право под държавна протекция и се опитват да задават тона не само в света на глобалната икономика, но и в международните отношения. Ирония на времето е създаването на цели глобални геопроекти с формални цели като свободна търговия, икономически ръст, достъп до пазари, платформа за регионална интеграция и т. н., чрез които ТНК утвърждават статута си и същевременно се опитват да ограничават влиянието на националните държави, с чийто инструменти просперират. Подобни глобални инициативи дават възможности на ТНК на САЩ да реализират максимално потенциала си, което със стандартните методи на Конгреса би било невъзможно и като обеми, и като темпове. ТНК запълват вакуум на сила, сигурност и власт само там, където могат чрез капиталите си да определят профила на икономиката и да моделират политическото пространство, т. е. в сравнително слаби икономически и политически нестабилни страни със слабо развит информационнокомуникационен потенциал, прилагайки друг тип политика към мощните национални държави.

Според методологията на съвременните международни отношения като глобални играчи могат да се дефинират не заявилите претенции, а тези, които реално могат да оказват давление, да го поддържат с реално упражнено влияние по отношение на световните центрове на икономиката и геополитиката, както и реално и постоянно да определят посоката на световното развитие.

Международните отношения днес са обект както на традиционните ресурсни предизвикателства, така и на заплахи с неполитически произход (пандемии, климатични промени). 
Съвременници сме на трансформиращата роля на различни центрове на сила и региони.

Съставът на „Висшата лига““ на световната политика се разшири и обнови. В следствие живеем в нова геополитическа конфигурация, при която старите правила не са актуални, но и пълен хаос е невъзможен и нежелан дори от „претендентите“.

ИЗПОЛЗВАНА ЛИТЕРАТУРА

Denchev 2019: Denchev, S. Informatsia i sigurnost. Sofia: Za bukvite - „O pismeneh“ “Денчев, С. Информация и сигурност. София: За буквите - „О писменех"].

Fukuyama 2018: Fukuyama. F. Ne sam si promenil mnenieto za liberalizma. // Figaro, 16. 04. 2018 [Фукуяма, Ф. Не съм си променил мнението за либерализма. // Фигаро, 16. 04. 2018] < https://www.pan.bg/view article49-427144-en-fukuyama-ne-sym-si-promenil-mnenieto-za-liberalizma.html (status 02.11.2021)>.

Georgiev /1/ 2018: Georgiev, B. Vstuplenie Bolgarii v Pervuyu mirovuyu voynu: k voprosu o vybore 1915 goda. // Sovremennaya nauchnaya mysly. Moskva, № 3, s. $42-59$ [Георгиев, Б. Вступление Болгарии в Первую мировую войну: к вопросу о выборе 1915 года. // Современная научная мысль. Москва, № 3 , c. 42-59].

Georgiev 2007: Georgiev, B. Liberalnata (radoslavistka) partia. Na vlast i v opozitsia (1899 - 1908). Sofia: Pleyada [Георгиев, Б. Либералната (радославистка) партия. На власт и опозиция. София: Плеяда].

Georgiev 2016: Georgiev, B. Mirazhat za „Velika Bulgaria”. Zhivotat i deynostta na d-r V. Radoslavov (1854 - 1929). Veliko Tarnovo: Ivis [Георгиев, Б. Миражът за „Велика България“. Животът и дейността на д-р В. Радославов (1854 - 1929). Велико Тьрново: Ивис].

Georgiev 2018: Georgiev, B. Rolyata na d-r V. Radoslavov za vklyuchvaneto na Bulgaria v Parvata svetovna voyna. - In: Istorikii. T. 11, Veliko Tarnovo: Faber, s. 147-178 [Георгиев, Б. Ролята на д-р В. Радославов за включването на България в Първата световна война. - В: Историкии. Т. 11, Велико Търново: Фабер, с. 147-178].

Georgiev 2020: Georgiev, B. Strategicheskoto znachenie na Chernomorskia region v politikata na balgarskite pravitelstva ot Saedinenieto do vklyuchvaneto na Bulgaria v Parvata svetovna voyna. - In: Drinovski sbornik. T. XIII, SofiaHarkov: M. Drinov, s. 118-139 [Георгиев, Б. Стратегическото значение на Черноморския регион в политиката на българските правителства от Съединението до включването на България в Първата световна война. В: Дриновски сборник. Т. ХІІІ, София: М. Дринов, с. 118-139].

Ilchev 1995: Ilchev, I. Rodinata mi: prava ili ne! Vanshnopoliticheskata propaganda na balkanskite strani (1821-1923). Sofia: UI „Sv. Kliment Ohridski““ [Илчев, 


\section{Годииник на ФХН, ХXXII A}

И. Родината ми: права или не! Външнополитическата пропаганда на балканските страни (1821-1923). София: УИ „Св. Климент Охридски“].

Mumford 2013: Mumford, A. Proxy Warfare. Cambridge: Polity Press.

Primakov 2007: Primakov, E. Blizkiyat iztok na stsenata i zad kulisite. Sofia: Forum „Balgaria - Rusia“ [Примаков, Е. Близкият изток на сцената и зад кулисите. София: Форум „България - Русия“].

Zlatanov 2016: Zlatanov, A. Teoretichni i pravni aspekti na deynostta na politseyskite organi po osiguryavane na obshtestvenia red pri masovi meropriyatia. Sofia: AMVR [Златанов, A. Теоретични и правни аспекти на дейността на политическите органи по организиране на обществения ред при масови мероприятия. София: АМВР]. 